\title{
Development of a High Strength Geopolymer by Novel Solar Curing
}

Minhao Dong, ${ }^{1 \dagger}$ Wei Feng, ${ }^{2 \dagger}$ Mohamed Elchalakani, ${ }^{1} *$ Gang (Kevin) Li, ${ }^{2} *$ Ali Karrech, ${ }^{1}$ Eric F. May ${ }^{2}$

${ }^{1}$ School of Civil, Environmental and Mining Engineering, The University of Western Australia, 35 Stirling Highway, Crawley, WA 6009, Australia.

${ }^{2}$ Centre for Energy, School of Mechanical \& Chemical Engineering, The University of Western Australia, 35 Stirling Highway, Crawley WA 6009, Australia

${ }^{\dagger}$ These authors contributed equally.

*Corresponding author. Email: kevin.li@uwa.edu.au; mohamed.elchalakani@uwa.edu.au

\begin{abstract}
Geopolymer is a popular construction material derived from different sources of aluminosilicates known for its environmental benefits and excellent durability in harsh conditions. However, the curing of fly-ash based geopolymer normally requires a thermal treatment that increases the manufacturing cost and carbon footprint. This paper explored a new economical and environmentally-friendly alternative, i.e. solar curing, that harnesses solar radiation to achieve accelerated geopolymerization process. Geopolymer mortars coated in two different greyscales namely solar curing black (SCB) and 40\% black (grey, SCG) were prepared to study the effect of solar radiation absorption ability on the strength of the specimens, along with ambient cured specimens (ATC) for comparison. Mechanical properties such as workability, compressive strength, stress-strain relationship from 1 day to 28 days were tested. The SCB specimens that can easily reach $65^{\circ} \mathrm{C}$ under the sun showed a substantial improvement of the compressive strength especially at the early age, i.e. 49.2 $\mathrm{MPa}$ at 1-day compared with 25.5 MPa for the ATC ones. At 28-day, SCB reached $92 \mathrm{MPa}$ in compressive strength which is $17.8 \%(13.9 \mathrm{MPa})$ higher than that of ATC. SCG showed a moderate enhancement in strength. Through in-depth physical and chemical
\end{abstract}


characterizations, the structure and morphology of geopolymers were identified through Xray diffraction (XRD), scanning electron microscope (SEM) and energy dispersive X-ray spectroscopy (EDS). It was found that geopolymer cured by solar radiation had more calcium aluminate silicate content hence leading to a higher mechanical strength. Furthermore, a titration study that determines the conversion rate of the activators inside geopolymers suggested a faster geopolymerization process in the solar cured specimens.

Keywords: geopolymer, solar curing, fly ash, activator, early age strength

\section{Highlights:}

1. Solar curing is a green and effective way to elevate curing temperature.

2. Solar curing has a significant effect on geopolymer hardening and strength.

3. The color of the geopolymers plays a significant role in hardening and strength.

4. High strength geopolymer (92 MPa) was achieved through solar curing. 


\section{Introduction}

Geopolymer was termed to describe the polymerization reaction of alkaline liquid (activator) and aluminosilicate of geological origin [1]. It was considered to replace the ordinary Portland cement as the third generation of cementitious materials [2]. The usage of fly ash as the source material (binder) in geopolymer composites was examined extensively for its advantages such as low cost and easy access. However, replacing the cement completely with fly ash caused new challenges such as the early age strength deficiency. Conventionally, this was resolved by elevating the curing temperature in an oven, which in turn imposed new challenges, such as high equipment cost and difficult synthesis. This negated the advantages of geopolymers in terms of cost and environment footprint. The novel solar curing method will be introduced in this paper to produce high strength geopolymers while lowering the greenhouse gases emission from the curing process.

The main constituent fly ash is the combustion residue collected from pulverized coal fired power plants. It is classified as ASTM Class C [3] to represent high calcium content and ASTM Class F [3] to represent low calcium content. Spherical fly ash particles reduce water demand and improve the workability of the geopolymer [4]. However, fly ash based geopolymer composite develops strength very slowly at early age due to the lack of calcium content. At room temperature, fly ash is not completely dissolved [5] and the low reactivity of the fly ash increases the setting time of the geopolymer. Therefore, to maintain an acceptable early age strength, methods that accelerate the curing process or modify the chemical reactions, which are heating curing and incorporating high calcium additives respectively, should be applied. Traditionally, oven curing at $60-120^{\circ} \mathrm{C}$ for an extended period [6-8], was introduced to accelerate early age strength. The duration was usually 24 hours [7], after which point the rate of increase in strength reduced to an uneconomical level [8]. Ultra-high strength specimens (120 MPa compressive strength) were obtained by heat 
curing at $115^{\circ} \mathrm{C}$ for 24 hours [9]. However, this method was only suitable for producing precast concrete structures, which were limited in size, cost and proximity to its designated location. Furthermore, despite of the slow polymerization process, the 56-day compressive strength of the ambient cured mixes is comparable to the ones that are heat cured [7]. Jang, Lee and Lee [10] produced fly ash based geopolymer in ambient environment with the binder, activator and superplasticizer only. However, the 28-day strength ambient-cured specimen was considerably lower than that of its oven-cured counterpart. More recently, to overcome the low reactivity of fly ash and reduce synthesis complexity, additives such as slag and various types of fibers were added to the geopolymer mix. Earlier researches were done to investigate the effect of adding slag on the chemical composition of the product. In 2003, Yip and Van Deventer [11] discovered that geopolymeric aluminosilicate hydrate (AS-H) gel and calcium silicate hydrate (C-S-H) gel were formed simultaneously and independently. The feasibility of ambient curing of low calcium (Class F) fly ash was tested and it was concluded that the addition of ground granulated blast-furnace slag (GGBS), ordinary Portland cement $(\mathrm{OPC})$ or $\mathrm{Ca}(\mathrm{OH})_{2}$ accelerated early age strength development therefore enabled the method of ambient curing [12]. In the contrary, an adverse impact of adding granulated lead smelter slag (GLSS) on geopolymer strength was also discovered [13]. However, finer GLSS would reduce the impact. Ultra-high strength geopolymer mortars (108 MPa) were produced in the ambient conditions by replacing 50\% of fly ash with slag [14]. Slag proved to provide additional calcium content that accelerated the polymerization process. Fast microwave curing was introduced using household microwave ovens [15]. 1 minute of high microwave output (850W) accelerated the formation of aluminosilicate bonds. Combined with higher concentration of $\mathrm{NaOH}$, porous structures formation was seen in the fly ash based geopolymer paste. In Table 1, a summary of the mix designs and their curing methods are shown. Some of which only specified the mixing ratios of the constituents. Thus, 
the weights were adjusted based on the assumption that the geopolymer mortar had a density of $1800 \mathrm{~kg} / \mathrm{m}^{3}$.

Recently, more questions were posed on the actual environment benefits of the geopolymers. A study stated that a mere $9 \%$ margin existed between the carbon emission between OPC and fly ash based geopolymers [16]. A huge proportion of emission occurred in elevating the curing temperature and the use of the alkaline solutions. On average $12.5 \%$ of $\mathrm{CO}_{2}$ was released during the curing phase for the geopolymer in contrast to less than $1 \%$ for the OPC. The activator solution accounted for up to $59.4 \%$ of the total emission [16]. The addition of slag proved to reduce the demand for the activator solution [17]. The novel solar curing method is aiming to reduce the cost and carbon emission by raising temperature. Utilizing the solar energy as a replacement of high temperature curing of geopolymers can provide a green way to produce high strength concrete at almost no additional cost. Combining the two approaches, the fly ash based geopolymer will have an accelerated strength development as well as reduced carbon emission. Another important advantage of this mix design that cannot be overlooked is the utilization of waste materials such as slag and fly ash. The risk of toxic leakage and the cost of disposal can be significantly reduced [17]. This method is potentially beneficial to the production of structures that have large surface areas such as airport runways, rigid pavements for industrial floors [18], wall panels and floor slabs in regions with large solar energy reserves. The fast acceleration in strength development from the solar heat can potentially benefit various applications. Similarly, the outcomes from this study will also benefit the study of geothermal curing, e.g. shotcrete in hot and humid deep underground mine sites. 


\section{Testing Program}

\section{Material properties}

In this study, the main constituent fly ash was acquired from Gladstone Power Plant, QLD Australia. GGBS was from Builder's Choice, WA Australia. D-grade sodium silicate solution $\left(\right.$ specific gravity $=1.53, \mathrm{SiO}_{2} / \mathrm{Na}_{2} \mathrm{O}$ modulus ratio $\left.=2.0\right)$ was acquired from PQ Australia. The fine aggregate was AFS 45/50 Bassendean sand belt dune sand originated from Gaskell Quarry, WA Australia. The sodium hydroxide powder was from Redox Pty Ltd. based in Perth, which was used to make sodium hydroxide solution one day prior to the experiment. Fig 1 shows the particle size distribution of fly ash, GGBS and sand. The chemical composition of raw materials is shown in Table 2 . The basicity coefficient $\left(K_{b}=(\mathrm{CaO}+\right.$ $\left.\mathrm{MgO}) /\left(\mathrm{SiO}_{2}+\mathrm{Al}_{2} \mathrm{O}_{3}\right)[19]\right)$ of the fly ash was 0.19 and the hydration modulus $(\mathrm{HM}=$ $\left.\left(\mathrm{CaO}+\mathrm{MgO}+\mathrm{Al}_{2} \mathrm{O}_{3}\right) / \mathrm{SiO}_{2}[19]\right)$ was 0.84 . In contrast, $\mathrm{K}_{\mathrm{b}}$ of GGBS was 1.03 with $\mathrm{HM}$ being 1.87. The high calcium content of GGBS was beneficial for geopolymer hardening. Fig 2 shows the scanning electron micrographs (SEM) of fly ash and GGBS. The fly ash consisted of spherical particles with smooth surface, while the GGBS consisted of irregular and angular particles similar to the previously published results [20,21].

\subsection{Mix design and mixing procedures}

The binder, which consisted of 50\% fly ash and 50\% GGBS, accounted for $31.2 \%$ of the total weight while the activator accounted for another $18.8 \%$. The fine aggregates made up $50 \%$ of the total weight. The nominal density was $1800 \mathrm{~kg} / \mathrm{m}^{3}$. The activator solution was obtained from mixing lab-made $12 \mathrm{M}$ sodium hydroxide solution with the pre-made sodium silicate solution at a ratio of $1: 2.5$.

The sodium silicate solution and sodium hydroxide solution were mixed in a PVC bucket at the given ratio. The mixture was shaken and vibrated for a minimum of half an hour to ensure 
complete reactions and a good consistency. In the meantime, the dry ingredients including fly ash, GGBS and sand were weighed and poured into another bucket at the required ratio. The dry mixture was then transferred to the Hobart A200 mixer from Hobart Food Equipment Co. Ltd., USA and mixed for 3 minutes at low speed $(61 \mathrm{rpm})$. The well-mixed activator solution was slowly poured into the mixing bowl. The wet mixing took up to 1 minute at low speed. Afterwards, the mixture was taken to a workbench for workability tests and molding. The molds were made of heat resisting PVC with internal diameter of $52 \mathrm{~mm}$ and internal height of $108 \mathrm{~mm}$.

\section{Curing methods}

Three curing methods were compared in this research. The ambient cured specimens were categorized as the control group. The temperature and humidity in the ambient curing room were kept constant at $21^{\circ} \mathrm{C}$ and $95 \%$ humidity. Two solar curing methods, namely SCB and SCG, were developed to simulate different testing environments. The SCG cylinders were painted with a shade of grey specifically matched to the color of the oven-cured specimens, corresponding to $40 \%$ black on the grey scale chart $(0 \%$ represents paper white and $100 \%$ represents solid black) [22]. The SCB cylinders were painted black (100\% black) and covered with a layer of bubble warp that had the bottom side painted black. The bubble side was facing towards the sun to create a greenhouse effect, which maximized the heat input. This was the ideal scenario to determine the maximum potential of the solar power in curing. In contrast, $\mathrm{SCG}$, intended as an economical alternative to SCB, was analyzed for its energy absorption ability in the geopolymer's natural color hence the feasibility of solar curing the unpainted and exposed geopolymers. The sample preparation of the three curing methods are shown in Fig 3. The solar cured specimens were positioned directly towards the sun. A low profile reduced the temperature fluctuations caused by wind. 


\subsection{Testing methods}

The main focus of this research was the benefits of solar curing on the hardening of the geopolymers. The cylinders were grouped into 1,3, 7, 14 and 28-day specimens and tested accordingly. Each group had sub-groups in terms of the curing method and each sub-group had 3 cylinders. Each cylinder was attached with a Kyowa KFGS-30 30 mm strain gauge from Kyowa Electronic Instruments Co., Ltd., Japan in the vertical direction, except the 1day specimens. Additionally, a horizontal strain gauge was attached to the selected 28-day specimens to obtain the Poisson's ratio. Another 3 specimens were produced with two thermocouples located on the surface and inside the specimen at mid height. The temperature was captured once every hour throughout the curing duration with Omega HH378 thermometer, Omega Engineering, Inc., USA. In total, 48 geopolymer mortar cylinders were synthesized.

\section{Workability}

The workability test was performed prior to molding in each batch. In total, 4 measurements from 4 different batches were taken. The custom made mini cone used for testing was manufactured with the same aspect ratio of the standard cone given in AS 1012.3.1 [23]. Its top and bottom inner diameters are $38 \mathrm{~mm}$ and $76 \mathrm{~mm}$ respectively. The height is $116 \mathrm{~mm}$.

\section{Unconfined compression test (UCS)}

After carefully polishing the top surface of the specimens, the density of all the specimens were taken under the procedures specified in ASTM C20-00 [24]. The UCS test was carried out according to AS 1012.9 [25] using the $600 \mathrm{kN}$ capacity Baldwin compression/tension machine, Baldwin Lima Hamilton Corp., USA. The specimens were loaded at a constant rate of $20 \mathrm{MPa} / \mathrm{min}$. The readings from the vertical strain gauges were used to produce stress- 
strain curves. The static chord modulus of elasticity and the Poisson's ratios were calculated based on AS 1012.17 [26].

\section{Titration}

The purpose of this study was to quantify the relationship between consumption of alkaline activator (sum of $\mathrm{NaOH}$ and $\mathrm{Na}_{2} \mathrm{SiO}_{3}$ ) and the curing conditions and time. Immediately after each strength test, $1 \mathrm{~g}$ of grounded geopolymer sample was soaked into $40 \mathrm{ml}$ of deionized water for 2 days at $30^{\circ} \mathrm{C}$, then $10 \mathrm{ml}$ of the resultant supernatants were collected and filtrated with Acrodisc ${ }^{\circledR} 25 \mathrm{~mm}$ syringe filter from Pall Corporation, USA $(0.45 \mu \mathrm{m}$ Supor® Membrane, Pall Corporation, USA) and titrated by diluted $\mathrm{HCl}$ solution $(0.1 \mathrm{~mol} / \mathrm{L})$. Phenolphthalein was chosen as the indicator to detect the end point, which turns from pink to colorless when $\mathrm{pH}=8.2$.

\section{XRD}

Powder samples were prepared immediately for XRD analysis by grinding dried tested specimens. The X-ray diffraction patterns were recorded by using a PANalytical Empyrean X-ray Diffractometer made in Netherlands with $\mathrm{Cu} \mathrm{K}$ radiation $(\lambda=1.5404 \AA), 40 \mathrm{kV}$ and 40 $\mathrm{mA}$ and scanning at $4-80^{\circ}$ in $2 \theta$ at rate of $2^{\circ}$ per minute.

\section{SEM and EDS}

The chips from the representative ATC, SCB and SCG specimens at 28 days were obtained after the compressive strength test and prepared for SEM analysis right away. Firstly, the chips were fixed on aluminum stubs with carbon tapes, followed by a thin layer of gold coating for microstructure imaging. The SEM imaging was performed by using Verios XHR SEM, FEI Company, USA, which was equipped with Oxford Instruments X-Max EDS Detector made in UK for microanalysis to better identify the main microstructural features of geopolymer specimens. 


\section{Mechanical Test Results}

Table 3 summarizes the key mechanical parameters of the mix design that are being investigated. $f_{c m}$ refers to the mean compressive strength of the sub-group while $f_{c}^{\prime}$ is the characteristic compressive strength with $95 \%$ confidence level.

\section{Workability}

The recorded flow diameters were $189 \mathrm{~mm}, 200 \mathrm{~mm}, 190 \mathrm{~mm}$ and $195 \mathrm{~mm}$ respectively. As the bottom-inner diameter $\left(\emptyset_{b}\right)$ of the testing mini cone is $76 \mathrm{~mm}$, the average flow diameter was 2.54 times $(193.5 \mathrm{~mm})$ of $\emptyset_{b}$. Despite of the good workability obtained in the lab environment, superplasticizer is recommended to be added to allow extra time for mixing, transporting and molding on site.

\section{Density}

The average density of the 45 specimens was $2188 \mathrm{~kg} / \mathrm{m}^{3}$ with a standard deviation of 17 $\mathrm{kg} / \mathrm{m}^{3}$. A good coefficient of variation of $0.78 \%$ was achieved. The real density was $21.5 \%$ higher than the nominal density.

\section{Temperature profiles}

The temperature in the ambient curing room was set at a constant $21^{\circ} \mathrm{C}$ as the reference temperature. The temperatures around, inside and on the surface of the SCB and SCG specimens were recorded with respect to time. The variations of the maximum daily temperatures in the duration of the experiment for each category are shown in Fig 4. The temperature in SCG cylinders was on average $37 \%$ more than the ATC cylinders while SCB cylinders led SCG cylinders by another $6.5 \%$. The first three days of curing is crucial in the development of the geopolymers. The activity of the fly ash increases when the temperature rises. The geopolymerization reactions are almost complete when the temperature reaches 
$60-90^{\circ} \mathrm{C}$ [27]. Although the overall temperature difference was small, the temperatures during the peak hours of the black cylinders were substantially higher than those of the grey cylinders. As shown in Fig 5, only the black cylinders passed the $60^{\circ} \mathrm{C}$ threshold. The solar exposure data taken from Australian Government Bureau of Meteorology [28] were amended to the figure. During summer, this is a green and cost-effective way to maintain a high temperature in the specimens thus a high level of activity of the materials.

\subsection{Compressive strength}

A fundamental parameter being investigated was the effect of solar curing on geopolymer strength and its development. In this study, a good consistency in strength was observed. All the sub-groups satisfied the favorable standard deviation of the compressive strength being less than $5 \mathrm{MPa}$. The geopolymer specimens at early age exhibited ductile behaviors under load while the later age specimens exhibited brittle behaviors. This can be seen in Fig 6, which shows the failures occurred in two examples. Such behavior was expected and resembled the typical failure modes of the OPC [29].

Fig 7 shows the compressive strength of each sub-group in each stage. It is obvious that solar curing had a positive effect on geopolymer strength. The early age strength gain was greatly assisted by the elevated temperature. Within 1 day, the SCB cylinders on average were already $93.3 \%(23.8 \mathrm{MPa})$ stronger than the control ATC cylinders. The SCG cylinders showed $70.2 \%(17.9 \mathrm{MPa})$ increase when compared with the control group. The respectable early age performance of 49.3 and $43.4 \mathrm{MPa}$ for black and grey cylinders will enable new possibilities for applications that require quick setting and fast strength gain.

The previous trend continued after 3 days, where at 7 days, the difference between the SCB cylinders and ATC cylinders was the largest at $32 \mathrm{MPa}(59.8 \%)$. In the meantime, the difference in strength between SCG and ATC cylinders was continuing to reduce as the 
development rate decreased. However, a 25.0\% (13.4 MPa) strength increment above the SCG specimens still existed. The SCB specimens achieved $85.5 \mathrm{MPa}$ in compressive strength after 7 days of solar curing. After 7 days, the rate of geopolymerization slowed down. As a result, the strength development curves of all the 3 groups flattened out and all the specimens were hardened at a similar gradual rate. At 28 day, specimen $28 \mathrm{SCB} 1$ reached $95.16 \mathrm{MPa}$ while specimen 28SCG1 reached 85.96 MPa. The reference ambient curing group had the highest reaching $80.17 \mathrm{MPa}(28 \mathrm{ATC} 2)$.

Solar curing is a green way to accelerate early age geopolymerization process hence the hardening rate. It also greatly improved the strength of the SCB cylinders due to the high peak temperature during the early age. The more economically feasible SCG cylinders showed a maximum of $17.9 \mathrm{MPa}(70.2 \%$ at 1 -day) increment over the control group and the increment gradually diminished as curing time increases. However, the early age strength advantages still allowed this curing method to be potentially applied to fast track constructions.

AS3972 [30] provides a hardening model for the OPC in the form of:

$$
f=\frac{t}{a+b t} f_{c m}
$$

where $t$ refers to the curing time and the coefficient $a$ and $b$ govern the shape of the hardening curve. For OPC, $a=4.0$ and $b=0.85$ [30].

It was found that such model was not suitable for geopolymer examined in this study. By running the least square method, 3 new sets of coefficients for the geopolymers cured by 3 different ways were introduced. In Table 4, a comparison between the coefficients for OPC and geopolymers is given. It is seen that a close resemblance between the SCB and SCG coefficients existed, which was expected due to the nature of the two methods. The higher overall strength of the SCB specimens was reflected by a smaller $b$. The ATC specimens had 
a weaker initial strength, as suggested by $a$. After the early age, the strength of the ATC cylinders resembled that of the SCG cylinders, which was reflected by $b$. Because of the same nature of geopolymer mixes, the equations can be simplified and generalized to suit a broader application. Fig. 7 shows a comparison between the measured hardening curves and those predicted using Eqs. 2 and 3 with the only difference being the parameter $(a)$ to compensate for the early age strength difference found for solar cured geopolymer.

$$
\begin{gathered}
f_{\text {ambient }}=\frac{t}{2.5+t} f_{c m} \\
f_{\text {solar }}=\frac{t}{1+t} f_{c m}
\end{gathered}
$$

\subsection{Stress-strain and Poisson's ratio}

A comparison between the stress-strain curves in each curing stage is shown in Fig 8. It is clearly seen that higher compressive strengths correlated with larger strains at the peak loads are obtained when heat supply was induced through solar radiation.

The stress-strain relationships of the three curing methods at 28 days were compared with the two existing approximation methods for OPC. Eq. 4 was proposed by Desayi and Krishnan [31] and Eq. 5 was proposed by Hognestad [32].

$$
\begin{gathered}
\sigma=\frac{E_{c} \varepsilon}{1+\left(\frac{\varepsilon}{\varepsilon_{0}^{\prime}}\right)^{2}} \\
\sigma=f_{c m}\left[2\left(\frac{\varepsilon}{\varepsilon_{0}^{\prime}}\right)-\left(\frac{\varepsilon}{\varepsilon_{0}^{\prime}}\right)^{2}\right]
\end{gathered}
$$

where $\varepsilon_{0}^{\prime}$ is the strain at the peak stress and $f_{c m}$ is the mean compressive strength.

The comparison is shown in Fig 9. It is obvious to notice that the approximations tend to take a broader and smoother shape whereas the geopolymers possess a different failure pattern. For the same strain, Eq. 4 and Eq. 5 tend to overestimate the stress of the geopolymer. 
Because the equations were intended for OPC, they may not be used for the prediction of the stress-strain relationships for geopolymers.

Therefore, we propose the following modification to Eq. 4:

$$
\sigma=\frac{0.65 E_{c} \varepsilon}{\left(1+\left(\frac{0.091 \varepsilon}{\varepsilon_{0}^{\prime}}\right)^{4}\right)^{3}}
$$

The new expression Eq. 6 appears more satisfactory than the standard equations for OPC that exhibit large discrepancies when applied to geopolymers.

The Poisson's ratio was obtained by $v=\varepsilon_{a} / \varepsilon_{h}$, where $\varepsilon_{a}$ is the measured axial strain and $\varepsilon_{h}$ is the measured lateral strain. The average Poisson's ratio of the specimens at 28 days was 0.2273 with a coefficient of variation of $13 \%$, which is in the typical range $(0.15-0.25)$ for OPC [29].

\section{Elastic modulus}

The static chord moduli of elasticity of the specimens are shown in Table 3 . Three equations for the OPC from various standards were used to predict the elastic modulus based on the compressive strength $\left(f_{c m}\right)$ and the density $(\rho)$. Eq. 7 and Eq. 8 are two models found in AS 3600 [33] and Eq. 9 was found in ACI 318 [34].

$$
\begin{gathered}
E_{c}=0.043 \rho^{1.5} \sqrt{f_{c m}} \\
E_{c}=5050 \sqrt{f_{c m}} \\
E_{c}=3320 \sqrt{f_{c}^{\prime}}+6900
\end{gathered}
$$

From the comparison shown in Table 3 between the measured and predicted elastic modulus, it may be concluded that using Eq. 9 provides more accurate predictions when compared to Eqs. 7 and 8. 


\section{Chemical test results}

\subsection{XRD analysis}

Fig 10 shows the X-ray diffraction patterns of major components of geopolymer: Gladstone fly ash and GGBS. The broad hump in the $2 \theta$ range of $28-35^{\circ}$ for as-received GGBS and 18 $28^{\circ}$ for as-received fly ash indicate that the original materials were mostly in amorphous phase. In addition, some crystalline peaks corresponding to quartz $\left(\mathrm{SiO}_{2}\right)$, mullite $\left(\mathrm{Al}_{6} \mathrm{Si}_{2} \mathrm{O}_{13}\right)$, magnetite $\left(\mathrm{Fe}_{2} \mathrm{O}_{3}\right)$ and hatrurite $\left(\mathrm{Ca}_{3} \mathrm{Si}_{1} \mathrm{O}_{5}\right)$ are present in the fly ash, while crystalline peaks of gypsum $\left(\mathrm{CaSO}_{4} \cdot 2 \mathrm{H}_{2} \mathrm{O}\right)$ and basanite $\left(\mathrm{CaSO}_{4} \cdot 0.5 \mathrm{H}_{2} \mathrm{O}\right)$ are present in the GGBS. Powder samples of three different curing conditions at 28 days were also analyzed using XRD to evaluate the changes in crystalline peaks and amorphous humps. The XRD patterns of 28-day geopolymer products are shown in Fig 11. In comparison with fly ash and GGBS in Fig 10, it can be noticed that some of the predominant peaks in fly ash and GGBS, such as peaks at $2 \theta$ angle of $11.6^{\circ}$ of GGBS and $29^{\circ}$ and $33.2^{\circ}$ of fly ash have disappeared in synthesized geopolymers. Moreover, the intensity of peaks at $2 \theta$ angle of $16.4^{\circ}, 33.2^{\circ}$ and $40.8^{\circ}$ is shown to be much lower after geopolymerization. These indicate that GGBS and fly ash have been dissolved in the geopolymerization process and formed an amorphous gel phase.

It is also important to note that peaks at $30^{\circ}$ were detected in all of the 28 -day geopolymer specimens, which are very closely associated with C-S-H $[35,36]$. As both the fly ash and GGBS were mixed as a binder in the present study, calcium from GGBS react to form calcium silicate hydrate $(\mathrm{C}-\mathrm{S}-\mathrm{H})$ or calcium aluminate silicate hydrate $(\mathrm{C}-\mathrm{A}-\mathrm{S}-\mathrm{H})$, which coexist with geopolymer sodium aluminate silicate hydrate gel (N-A-S-H) due to complex reaction mechanism $[37,38]$. C-S-H gel and C-A-S-H gel can decrease the porosity, thus 
usually improves the compressive strength of final products when coexist with NASH gel [39]. When comparing intensity of peaks at $30^{\circ}$ for these three specimens, it can be observed that intensity from high to low is in the order of: $28 \mathrm{SCB}, 28 \mathrm{SCG}, 28 \mathrm{ATC}$, indicating more CS-H and C-A-S-H gel formed under solar heat curing than ambient curing. This could explain the highest compressive strength shown by $28 \mathrm{SCB}(92.0 \mathrm{MPa})$, followed by $28 \mathrm{SCG}$ (80.4MPa) and 28ATC (78.1MPa) in this study. The presence of C-S-H and relatively high compressive strength is in line with the previous research[21,40].

\subsection{SEM and EDS analysis}

The SEM images and EDS spectrums of geopolymer specimens 28ATC, 28SCG and 28SCB are shown in Fig 12. Geopolymers with solar heat curing (28SCG, 28SCB) showed less number of unreacted fly ash particles (marked as symbol "F") but more partially reacted hollow fly ash sphere (marked as " $\mathrm{H}$ ") and the matrix appeared denser and more homogeneous than 28ATC, implying fly ash is relatively slow to react at ambient temperature, and with solar heat curing the strength development was effectively accelerated $[37,41]$.

From the EDS spectrum, it can be deduced that the curing temperature of the mixtures has no substantial effect on the mineralogical composition of the products. Since the calcium, sodium, silicon and aluminum were present in all three geopolymer specimens, indicating for different curing conditions that the two main reaction products are amorphous sodium aluminosilicate gel (N-A-S-H) and calcium silicate hydrate (C-A-S-H or C-S-H) [37,42]. However, the EDS diagrams of $28 \mathrm{SCG}$ and $28 \mathrm{SCB}$ show a relatively higher count especially for calcium element together with and silicon, aluminum and oxygen elements, which can be 
attributed to more dissociation of $\mathrm{Al}, \mathrm{Si}$ and $\mathrm{Ca}$ ions from fly ash and GGBS under higher curing temperature in alkaline medium and their further participation in the $\mathrm{C}-\mathrm{A}-\mathrm{S}-\mathrm{H}$ gel formation. Moreover, the N-A-S-H and C-A-S-H are also confirmed by EDS quantification study. The major elements ratio is shown in Table 5. The average atomic ratios were close to $\mathrm{Ca} / \mathrm{Si} \sim 0.7-0: 8, \mathrm{Al} / \mathrm{Ca} \sim 0.5-0.55, \mathrm{Si} / \mathrm{Al} \sim 2-3$, corresponding to a calcium silicate hydrated, rich in $\mathrm{Al}$, includes $\mathrm{Na}$ in its structure [37]. The increase in $\mathrm{Al}$ and $\mathrm{Ca}$ content further proved more C-A-S-H formed under solar heated curing.

\subsection{Titration analysis}

The activator conversion rate of respective geopolymer specimens are present in Fig 13, which was calculated by:

$$
\text { Activator conversion rate } \%=\frac{\text { original total alkalinity }}{\text { (original total alkalinity-residual total alkalinity) }} \times 100 \%
$$

According to mass ratio of $\mathrm{NaOH}$ and $\mathrm{Na}_{2} \mathrm{Si}_{2} \mathrm{O}_{5}$ (1:2.5), we could calculate, for each cylinder (average weight of 500g), the original total alkalinity was equal to $1 \mathrm{~mol}$ of $\mathrm{OH}-$. The residual total alkalinity (see Table 6), which represents the unreacted activator in each specimen at each stage, was obtained by the amount of $\mathrm{HCl}$ consumed (mol) during titration. It can be noticed that the activator conversion rate gradually increased from 1 day to 14 days, meaning more and more $\mathrm{NaOH}$ and $\mathrm{Na}_{2} \mathrm{SiO}_{3}$ participated into geopolymer formation along with curing process, contributing to the higher compressive strength. Moreover, no matter at which stage, when comparing solar heated curing and ambient curing, the former always presents higher activator conversion rate than the latter, further supporting the conclusion obtained from XRD and SEM-EDS analysis that higher curing temperature accelerated the reaction between fly ash, slag and alkaline activator. A marginal higher or comparable activator conversion rate has been observed for SCB than SCG due to the small temperature difference between these two. 


\section{Conclusion}

The purpose of replacing OPC with geopolymer is to reduce carbon footprint, pollution and cost while benefiting from better durability and strength. To further improve strength and reduce cost, the novel solar curing method was proposed. Conclusions can be drawn on this new method of curing.

1. When compared with the control (ATC) group, both solar cured (SCB and SCG) groups exhibited faster early age strength development. The different reduced as curing duration prolonged.

2. The greenhouse effect treated SCB group still maintained a $17.8 \%(13.9 \mathrm{MPa})$ increment at 28-day over the ATC specimens (14.4\% or 11.6 MPa over the SCG group). The average compressive strength was $92 \mathrm{MPa}$ at 28-day.

3. SCG, which represents the performance of geopolymer products in their natural color under solar curing, had significantly higher early age strength (17.9 $\mathrm{MPa}$ or $70.2 \%$ at 1-day) than the ATC specimens. Applications such as shotcrete can be examined further in the future.

4. The solar radiation accelerated geopolymer displayed distinctive characteristics and required its own set of standards. A new hardening curve was proposed to compensate for the high early age strength. Additional experiments can be carried out to model the elastic modulus.

5. The XRD analysis, SEM and EDS results for as-synthesized geopolymers all confirmed the formation of mixture of C-A-S-H and N-A-S-H gel. More C-A-S-H gel was proved to be produced under solar heated curing, which can reduce the porosity therefore improve the compressive strength, agreeing with observed mechanical behavior. 
6. Titration method was introduced to analyses the relationship between activator conversion rate and curing duration and temperature. As a result of the elevated curing temperature, a larger amount of sodium hydroxide and sodium silicate was involved in the geopolymerization process of SCB and SCG, which ultimately contributed to the higher strength.

\section{Acknowledgements}

This research was supported by the Australian Research Council through GL's Discovery Early Career Researcher Award (Grant no. DE140101824), and the Industrial Transformation Training Centre program (Grant no. IC150100019). The authors are thankful to UWA technicians Matt Arpin, Malcolm Stafford, Jim Waters and Brad Rose for assisting the students in performing the experiments. Thanks are given to Baikai Ma, Eddy Huang for assisting in the mixing of the geopolymers.

\section{References}

[1] J. Davidovits, High-Alkali Cements for 21st Century Concretes, Am. Concr. Inst. 144 (1994) 383-398.

[2] B. Singh, G. Ishwarya, M. Gupta, S.K. Bhattacharyya, Geopolymer concrete: A review of some recent developments, Constr. Build. Mater. 85 (2015) 78-90.

[3] ASTM C618-15, Standard Specification for Coal Fly Ash and Raw or Calcined Natural Pozzolan for Use in Concrete, ASTM International, West Conshohocken, PA, 2015. doi: 10.1520/C0618-15.

[4] A.S. Sayyad, S. V Patankar, Effect of Steel Fibres and Low Calcium Fly Ash on Mechanical and Elastic Properties of Geopolymer Concrete Composites, Indian J. 
Mater. Sci. 2013 (2013). doi: 10.1155/2013/357563.

[5] C. Chen, W. Gong, W. Lutze, I.L. Pegg, J. Zhai, Kinetics of fly ash leaching in strongly alkaline solutions, J. Mater. Sci. 46 (2011) 590-597.

[6] P. Chindaprasirt, T. Chareerat, High-strength geopolymer using fine high-calcium fly ash, J. Mater. Civ. Eng. 23 (2010) 264-271.

[7] M. Albitar, P. Visintin, M.S. Mohamed Ali, M. Drechsler, Assessing behaviour of fresh and hardened geopolymer concrete mixed with Class-F fly ash, KSCE J. Civ. Eng. (2014). doi: 10.1007/s12205-014-1254-Z.

[8] N.A. Lloyd, B. V. Rangan, Geopolymer Concrete with Fly Ash, Second Int. Conf. Sustain. Constr. Mater. Technol. 3 (2010) 1493-1504.

[9] C.D. Atiş, E.B. Görür, O. Karahan, C. Bilim, S. İlkentapar, E. Luga, Very high strength (120MPa) class F fly ash geopolymer mortar activated at different $\mathrm{NaOH}$ amount, heat curing temperature and heat curing duration, Constr. Build. Mater. 96 (2015) 673-678.

[10] J.G. Jang, N.K. Lee, H.K. Lee, Fresh and hardened properties of alkali-activated fly ash/slag pastes with superplasticizers, Constr. Build. Mater. 50 (2014) 169-176.

[11] C.K. Yip, J.S.J. Van Deventer, Microanalysis of calcium silicate hydrate gel formed within a geopolymeric binder, J. Mater. Sci. 38 (2003) 3851-3860.

[12] P. Nath, P.K. Sarker, V.B. Rangan, Early age properties of low-calcium fly ash geopolymer concrete suitable for ambient curing, Procedia Eng. 125 (2015) 601-607.

[13] M. Albitar, M.S. Mohamed Ali, P. Visintin, M. Drechsler, Effect of granulated lead smelter slag on strength of fly ash-based geopolymer concrete, Constr. Build. Mater. 83 (2015) 128-135. 
[14] M.Z.N. Khan, F. uddin A. Shaikh, Y. Hao, H. Hao, Synthesis of high strength ambient cured geopolymer composite by using low calcium fly ash, Constr. Build. Mater. 125 (2016) 809-820.

[15] S. Onutai, S. Jiemsirilers, P. Thavorniti, T. Kobayashi, Fast microwave syntheses of fly ash based porous geopolymers in the presence of high alkali concentration, Ceram. Int. 42 (2016) 9866-9874.

[16] L.K. Turner, F.G. Collins, Carbon dioxide equivalent (CO2-e) emissions: A comparison between geopolymer and OPC cement concrete, Constr. Build. Mater. 43 (2013) 125-130.

[17] G. Habert, J.B. D’Espinose De Lacaillerie, N. Roussel, An environmental evaluation of geopolymer based concrete production: Reviewing current research trends, J. Clean. Prod. 19 (2011) 1229-1238.

[18] J. Aldred, J. Day, Is Geopolymer Concrete a Suitable Alternative To Traditional Concrete ?, 37th Conf. Our World Concr. Struct. (2012) 1-14.

[19] H.Y. Leong, D.E.L. Ong, J.G. Sanjayan, A. Nazari, Suitability of Sarawak and Gladstone fly ash to produce geopolymers: A physical, chemical, mechanical, mineralogical and microstructural analysis, Ceram. Int. 42 (2016) 9613-9620.

[20] S.A. Memon, T.Y. Lo, S.A. Barbhuiya, W. Xu, Development of form-stable composite phase change material by incorporation of dodecyl alcohol into ground granulated blast furnace slag, Energy Build. 62 (2013) 360-367.

[21] T. Phoo-Ngernkham, A. Maegawa, N. Mishima, S. Hatanaka, P. Chindaprasirt, Effects of sodium hydroxide and sodium silicate solutions on compressive and shear bond strengths of FA-GBFS geopolymer, Constr. Build. Mater. 91 (2015) 1-8. 
[22] L.A.B. Garo., Lesson 3: Color Mixing; Production \& Printing of Color, (1999). http://www.uncc.edu/lagaro/cwg/color/color_mixing.html (accessed May 13, 2017).

[23] AS 1012.3.1, Methods of testing concrete - Determination of properties related to the consistency of concrete - Slump test, Standards Australia, 2014.

[24] ASTM C20-00, Standard Test Methods for Apparent Porosity, Water Absorption, Apparent Specific Gravity, and Bulk Density of Burned Refractory Brick and Shapes by Boiling Water, ASTM International, West Conshohocken, PA, 2015. doi: 10.1520/C0020-00R15.

[25] AS 1012.9, Methods of testing concrete - Compressive strength tests - Concrete, mortar and grout specimens, Standards Australia, 2014.

[26] AS 1012.17, Methods of testing concrete - Determination of the static chord modulus of elasticity and Poisson's ratio of concrete specimens, Standards Australia, 1997.

[27] D. Hardjito, S.E. Wallah, D.M.J. Sumajouw, B.V. Rangan, On the development of fly ash-based geopolymer concrete, ACI Mater. J. 101 (2004) 467-472.

[28] Australian Government Bureau of Meteorology, Climate Data Online, (2013). http://www.bom.gov.au/climate/data/index.shtml?bookmark=203.

[29] R.F. Warner, B.B. Rangan, A.S. Hall, K.A. Faulkes, Concrete Structures, Longman, South Melbourne, Australia, 1998.

[30] AS 3972, General purpose and blended cements, Standards Australia, 2010.

[31] P. Desayi, S. Krishnan, Equation for the Stress-strain Curve of Concrete, J. Am. Concr. Inst. 61 (1964) 345-350.

[32] E. Hognestad, A Study of Combined Bending and Axial Load in Reinforced Concrete 
Members, 1951. doi: 10.14359/7785.

[33] AS 3600, Concrete structures, Standards Australia, 2009.

[34] ACI 318, Building Code Requirements for Structural Concrete and Commentary, 2014.

[35] N.K. Lee, G.H. An, K.T. Koh, G.S. Ryu, Improved Reactivity of Fly Ash-Slag Geopolymer by the Addition of Silica Fume, Adv. Mater. Sci. Eng. 2016 (2016). doi: $10.1155 / 2016 / 2192053$.

[36] S.A. Bernal, J.L. Provis, B. Walkley, R. San Nicolas, J.D. Gehman, D.G. Brice, A.R. Kilcullen, P. Duxson, J.S.J. Van Deventer, Gel nanostructure in alkali-activated binders based on slag and fly ash, and effects of accelerated carbonation, Cem. Concr. Res. 53 (2013) 127-144.

[37] F. Puertas, A. Fernández-Jiménez, Mineralogical and microstructural characterisation of alkali-activated fly ash/slag pastes, Cem. Concr. Compos. 25 (2003) 287-292.

[38] C.K. Yip, G.C. Lukey, J.S.J. Van Deventer, The coexistence of geopolymeric gel and calcium silicate hydrate at the early stage of alkaline activation, Cem. Concr. Res. 35 (2005) 1688-1697.

[39] X.Y. Zhuang, L. Chen, S. Komarneni, C.H. Zhou, D.S. Tong, H.M. Yang, W.H. Yu, H. Wang, Fly ash-based geopolymer: Clean production, properties and applications, J. Clean. Prod. 125 (2015) 253-267.

[40] S.K. Nath, S. Kumar, Influence of iron making slags on strength and microstructure of fly ash geopolymer, Constr. Build. Mater. 38 (2013) 924-930.

[41] O. Arioz, Effect of elevated temperature curing on properties of alkali-activated slag concrete, Cem. Concr. Res. 29 (1999) 1619-1625. 
[42] M. Chi, R. Huang, Binding mechanism and properties of alkali-activated fly ash/slag mortars, Constr. Build. Mater. 40 (2013) 291-298. 


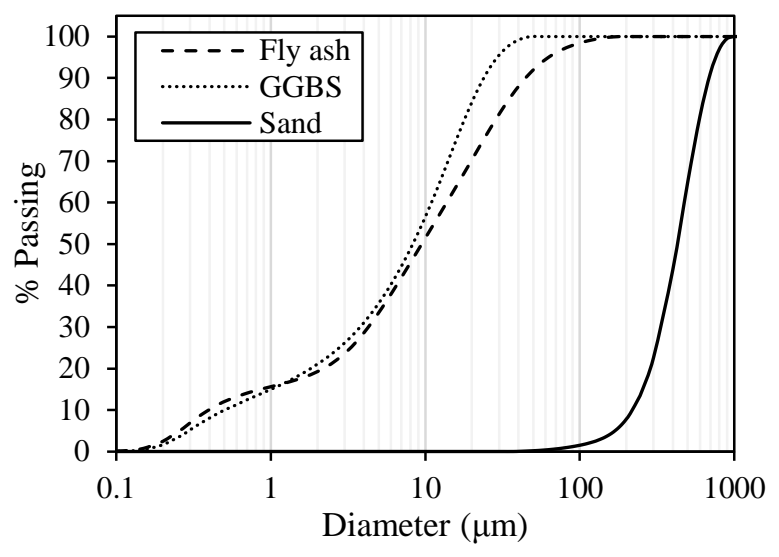

Figure 1 Particle size distribution of fly ash, slag and sand
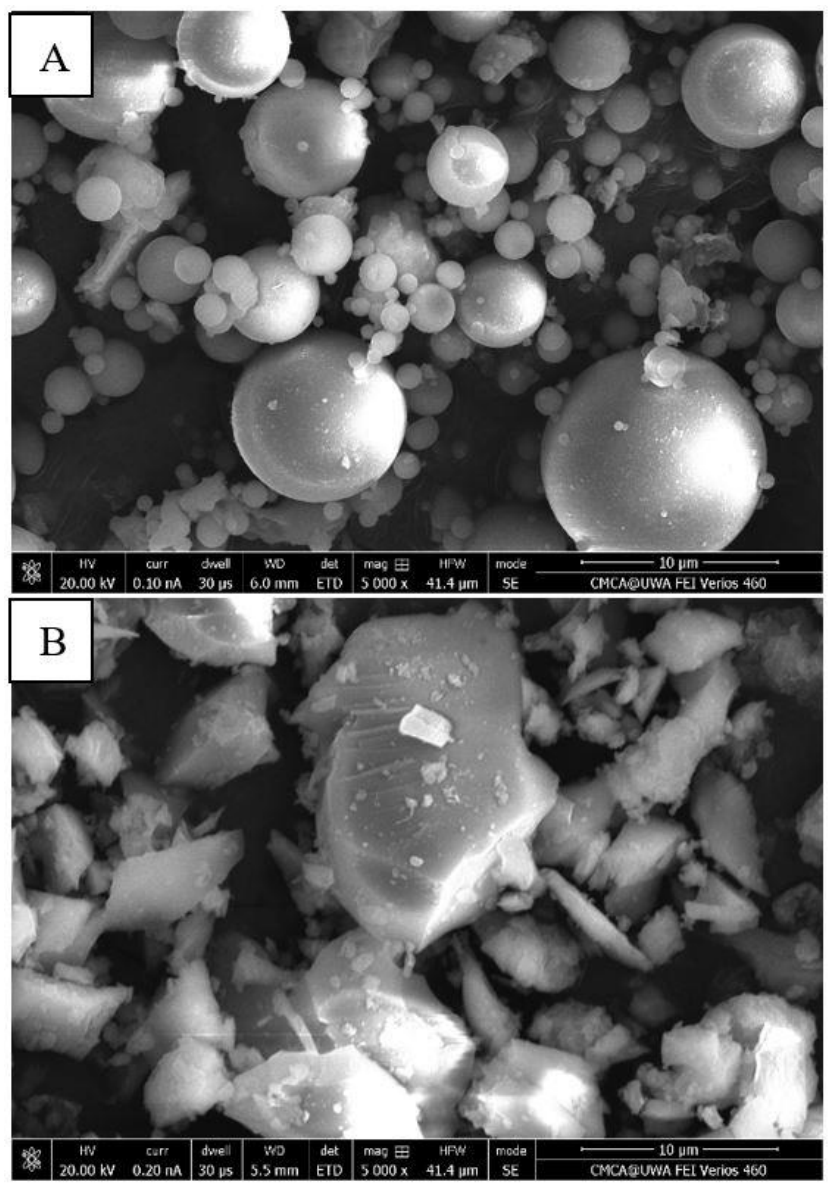

Figure 2 SEM images of the (A) fly ash and (B) slag 


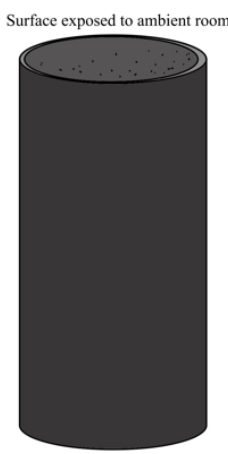

ATC

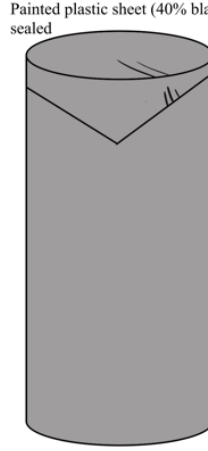

SCG

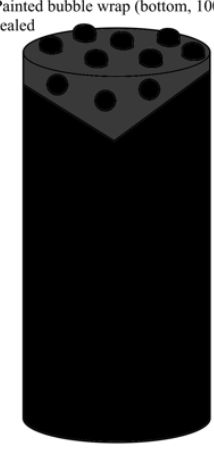

SCB

Figure 3 The sample preparation for each curing method

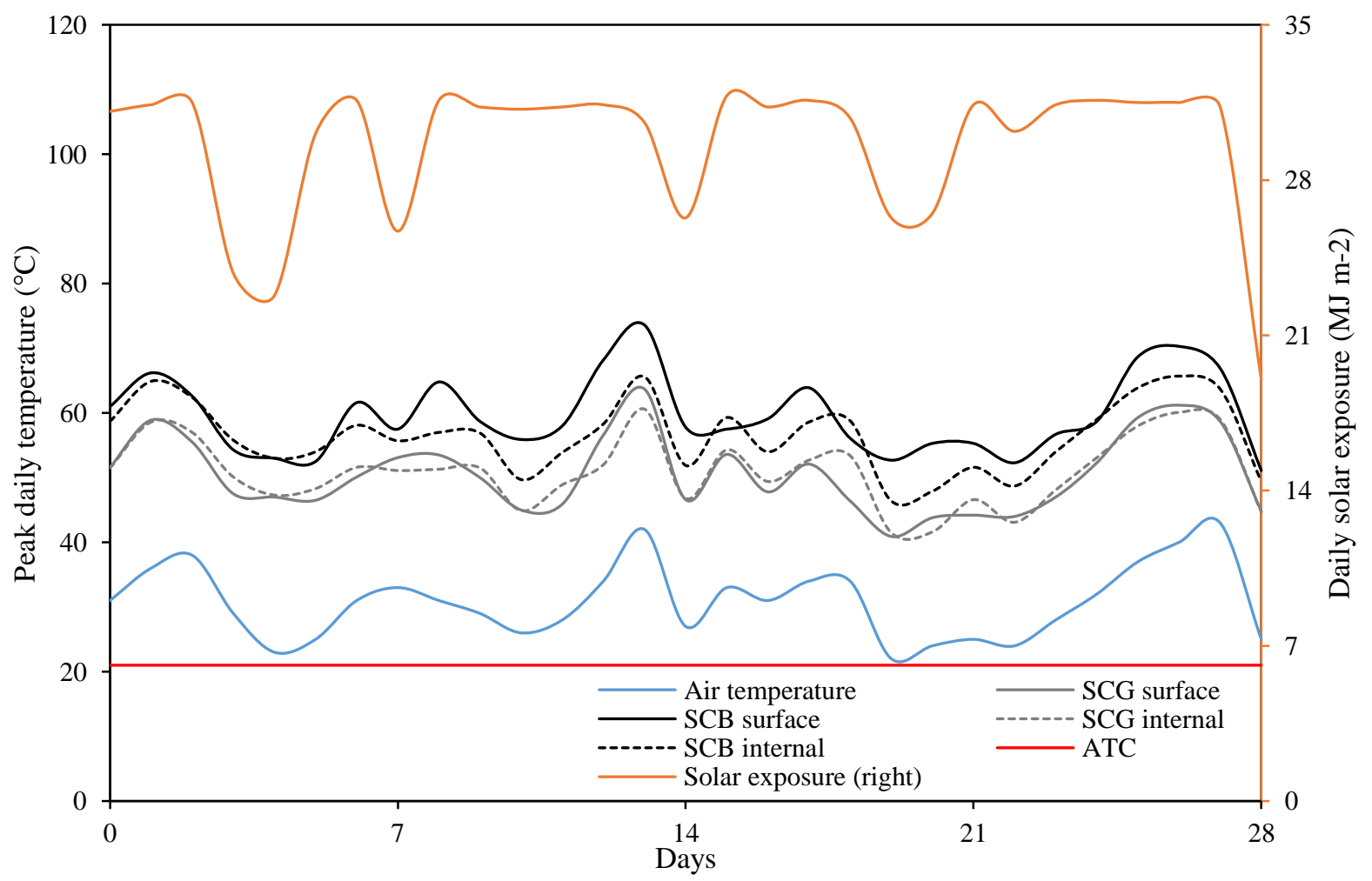

Figure 4 Records of daily peak temperatures in relation to solar exposure level 


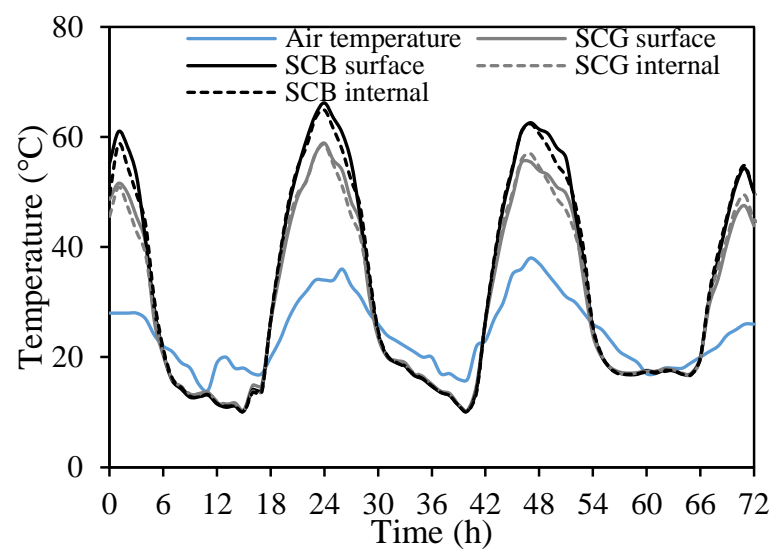

Figure 5 The temperature variation for the first three days

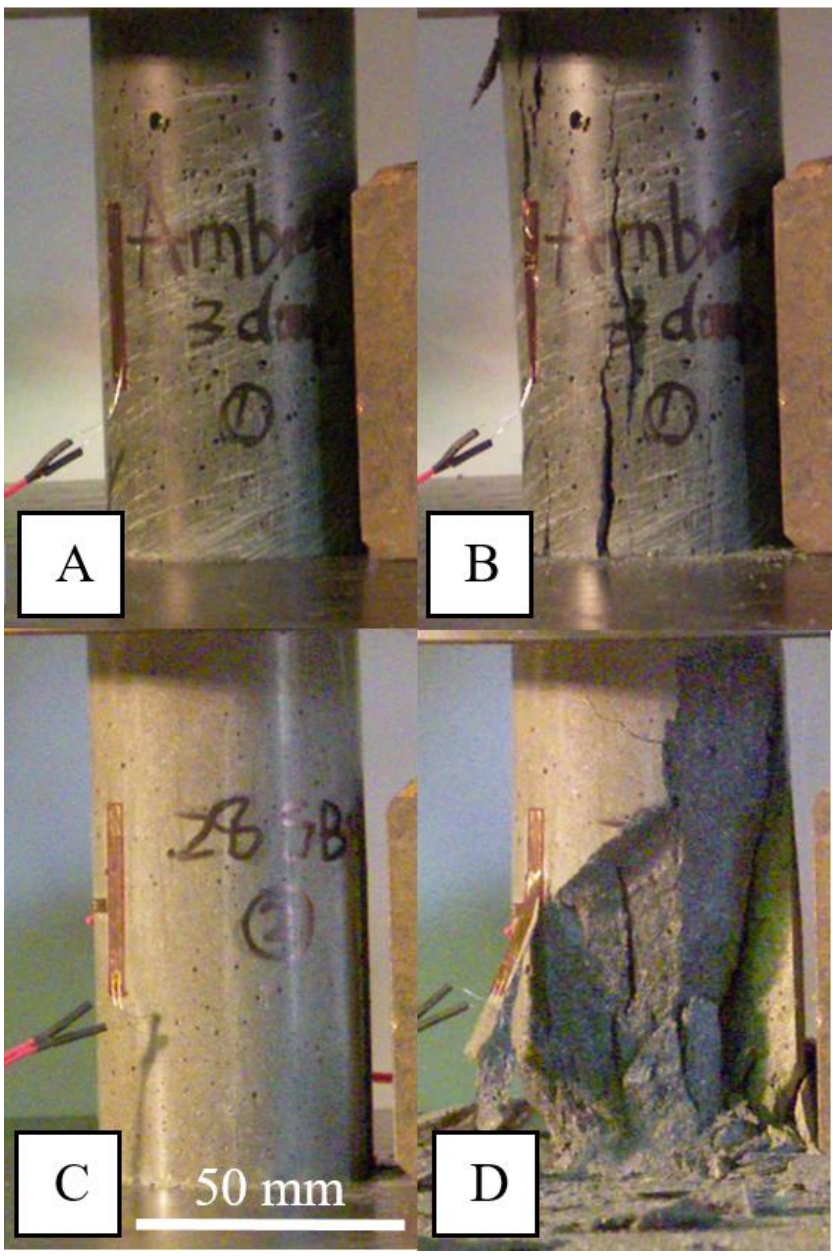

Figure 6 Images taken from the compressive strength test. A: 3ATC1 before test; B: 3ATC1 after test; C: $28 S C B 2$ before test; D: $28 S C B 2$ after test. 


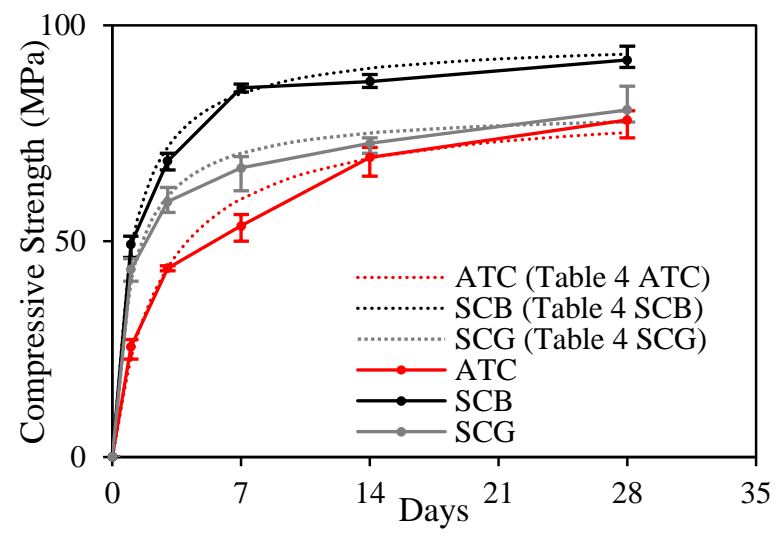

Figure 7 The hardening curves of the geopolymer specimens compared against the modified hardening curves (Eq. 1) with coefficients $a$ and $b$ found in Table 4

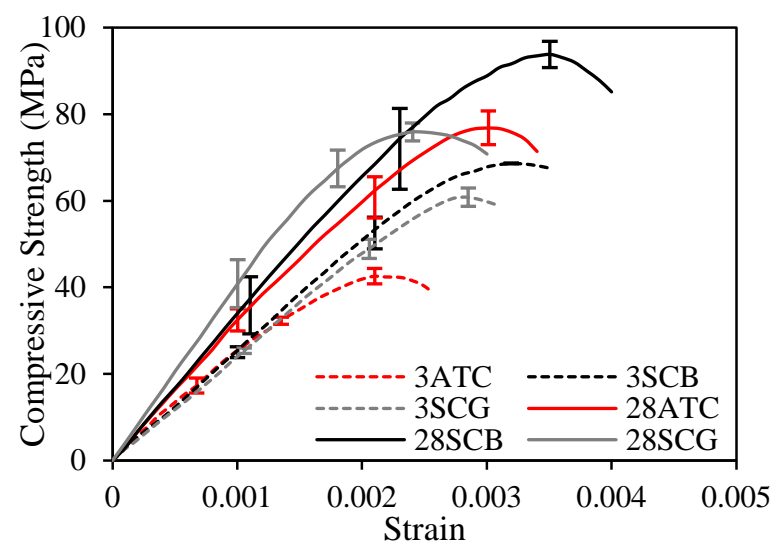

Figure 8 The stress-strain relationships of the various geopolymer specimens

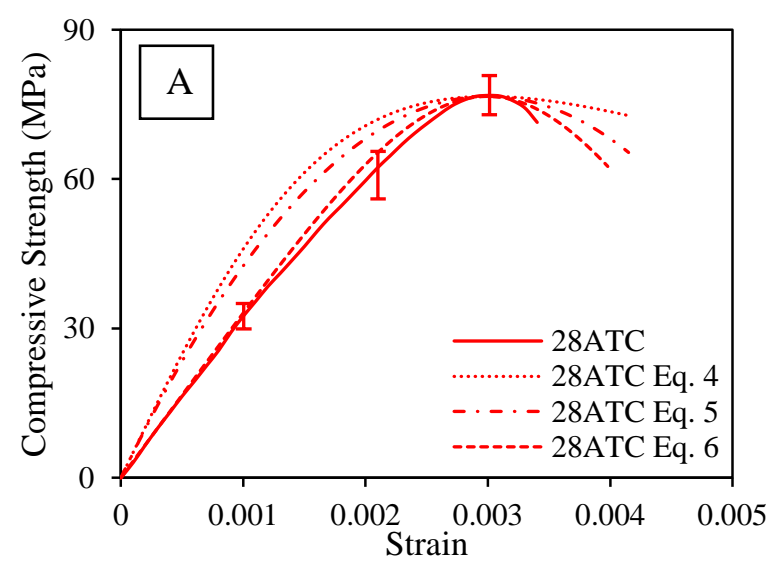



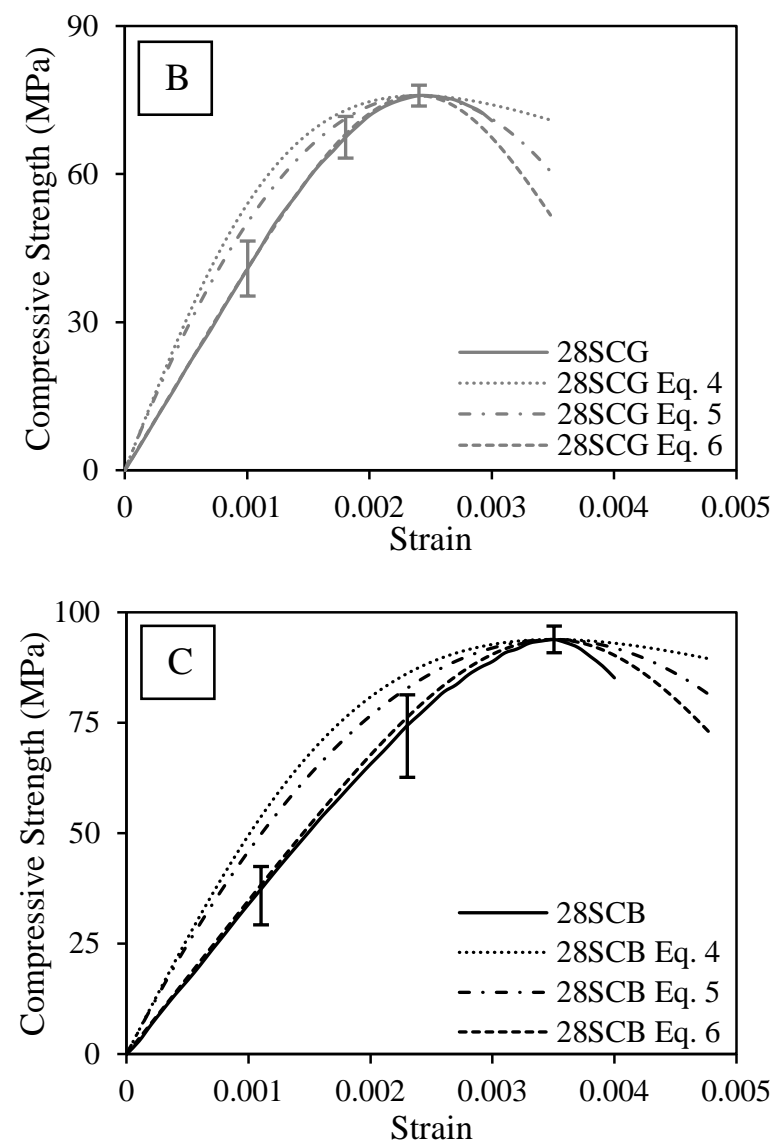

Figure 9 The stress-strain relationships of (A) ATC, (B) SCG and (C) SCB as compared with Eq. 4, Eq. 5 and the proposed Eq. 6

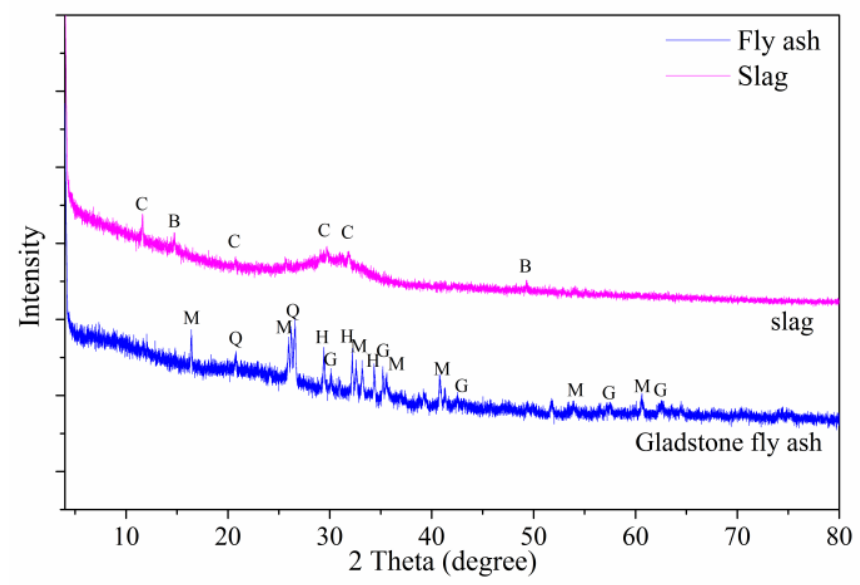

Figure 10 XRD patterns of Gladstone fly ash and slag (B-Basanite; Q-Quartz low; M-Mullite; G-Magnetite; H-Hatrurite; C-Gypsum) 


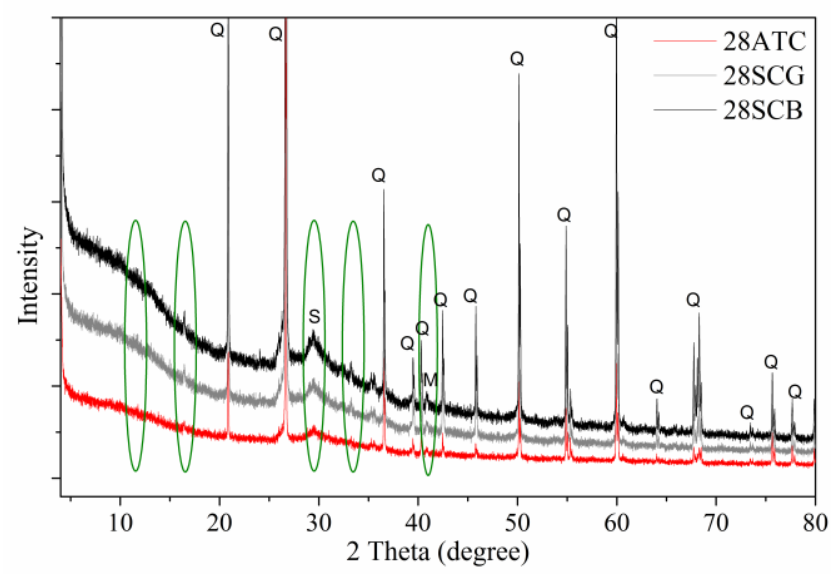

Figure 11 XRD patterns of geopolymer specimens synthesized by ambient curing (ATC) and solar curing (SCG and SCB) at 28 days ( $S$ - calcium silicate hydrate)
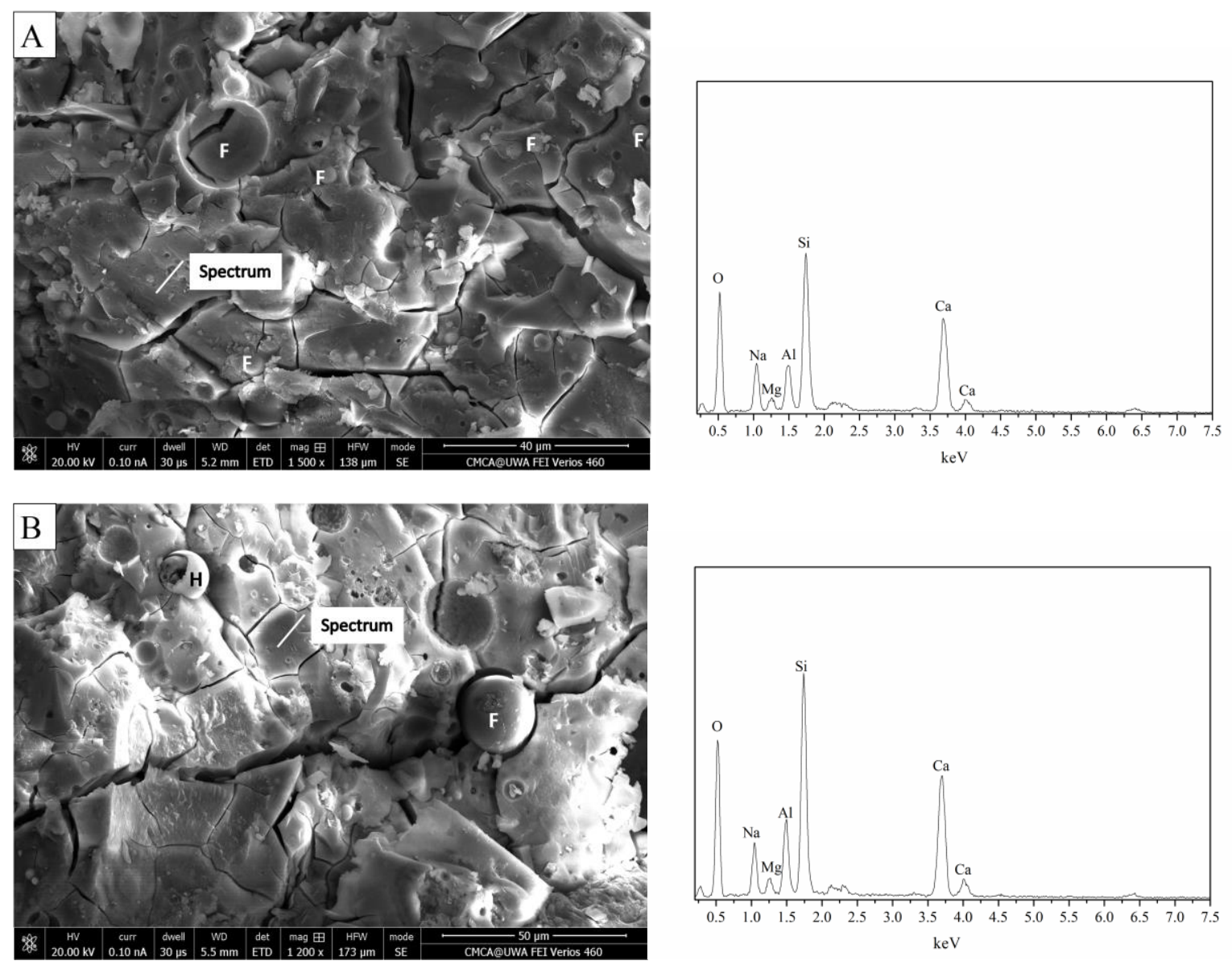

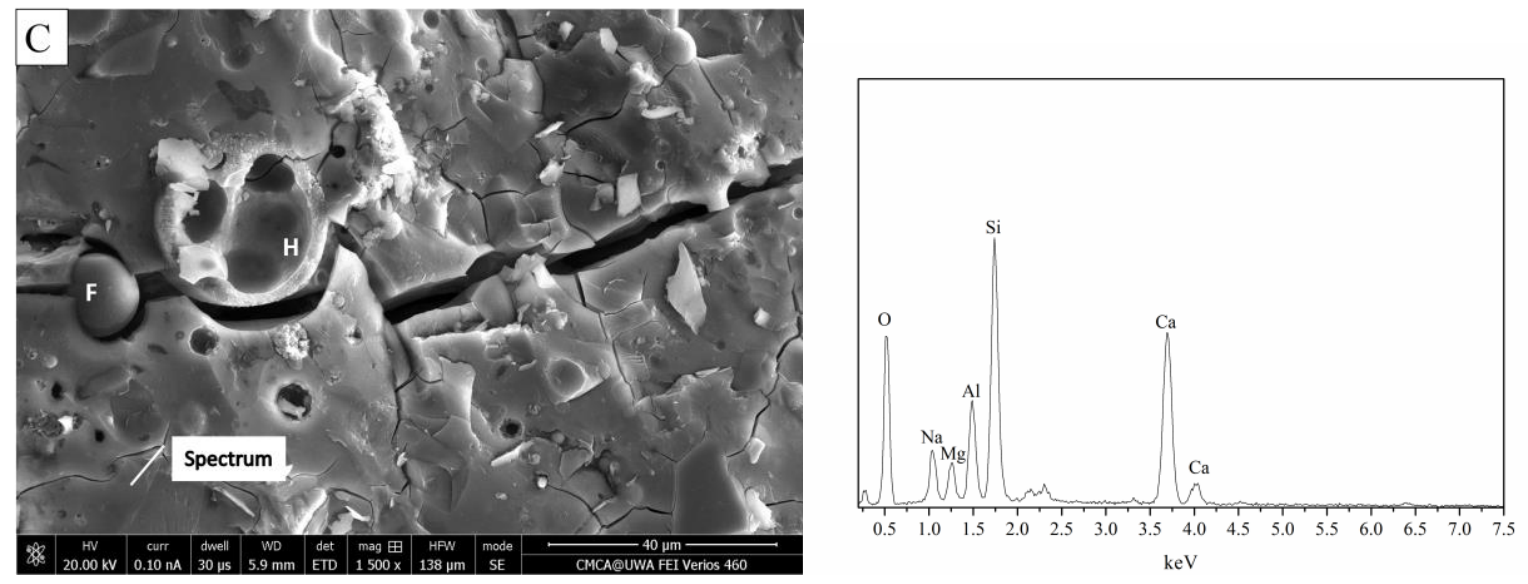

Figure 12 SEM/EDS spectrum of final geopolymer products (A) 28ATC, (B) $28 S C G$ and (C) $28 S C B$

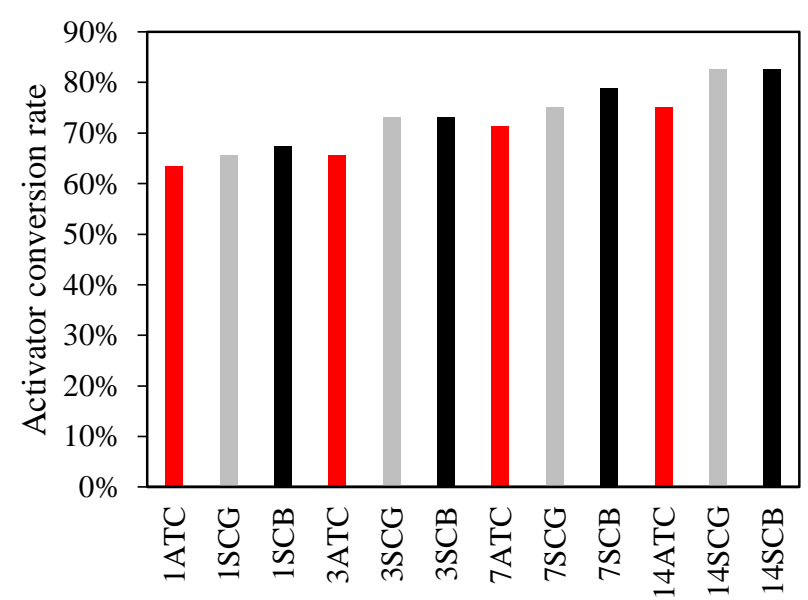

Figure 13 Activator conversion rate after 1 day, 3 days, 7 days and 14 days of curing for both ambient (ATC) and solar curing (SCG and SCB) specimens 
Table 1 A review of mix designs and their curing methods

\begin{tabular}{|c|c|c|c|c|c|c|c|c|c|c|c|}
\hline Author & Binder & Activator & SP & Water & $\mathrm{CA}$ & FA & $\mathrm{n} / \mathrm{s}$ & $\mathrm{M}_{\mathrm{NaOH}}$ & Curing & $\begin{array}{c}\text { Max Comp } \\
\text { Strength (MPa) }\end{array}$ & Comments \\
\hline $\begin{array}{l}\text { Lloyd, N. A., \& Rangan, B. V. } \\
\text { (2010) }\end{array}$ & 408 & 144 & 6 & 0 & 1294 & 554 & 2.50 & 8 & HC $6024 \mathrm{~h}$ & - & \\
\hline $\begin{array}{l}\text { Albitar, M., Visintin, P., } \\
\text { Mohamed Ali, M. S., \& } \\
\text { Drechsler, M. (2014) }\end{array}$ & 424.8 & 158.4 & $0-48$ & $0-60$ & $\begin{array}{c}1168.8- \\
1200\end{array}$ & $\begin{array}{c}580.8- \\
600\end{array}$ & 1.50 & 14 & $\mathrm{HC} 7024 \mathrm{~h}$ & 3-day: 74.5 & \\
\hline $\begin{array}{c}\text { Albitar, M., Mohamed Ali, M. } \\
\text { S., Visintin, P., \& Drechsler, M. } \\
\text { (2015) }\end{array}$ & 424.8 & 156.7 & 31.2 & 9.84 & 1180.8 & 595.2 & 1.50 & 14 & HC $7024 h$ & 7-day: 66.78 & $\begin{array}{c}\text { Binder FA GLSS, Fine aggregates } \\
\text { WRS GLSS }\end{array}$ \\
\hline $\begin{array}{l}\text { Jang, J. G., Lee, N. K., \& Lee, } \\
\text { H. K. (2014) }\end{array}$ & $\begin{array}{c}1176.6- \\
1291.1\end{array}$ & $\begin{array}{c}588.3- \\
645.6\end{array}$ & $0-51.6$ & 0 & 0 & 0 & 2.00 & 4 & AC $2024 \mathrm{~h}$ & 28-day: 61 & $\begin{array}{l}\text { SP: naphthalene-based and } \\
\text { polycarboxylate-based }\end{array}$ \\
\hline $\begin{array}{c}\text { Chindaprasirt, P., \& Chareerat, } \\
\text { T. (2010)** }\end{array}$ & 415.7 & 207.9 & 0 & 33.3 & 0 & 1143.2 & 1 & 10 & $\begin{array}{l}\text { HC } 30-9048 \mathrm{~h}, \text { delayed for } \\
\text { one hour }\end{array}$ & 28-day: 84 & Fine high-calcium fly ash \\
\hline $\begin{array}{l}\text { Khan, M. Z. N., Shaikh, F. } \\
\text { uddin A., Hao, Y., \& Hao, H. } \\
(2016)^{* *}\end{array}$ & 562.5 & 337.5 & 0 & 0 & 0 & 900 & 2.5 & 12 & AC $2324 h$ & 28-day: 108 & Fly ash, Slag, $\mathrm{Ca}(\mathrm{OH}) 2$, UFFA \\
\hline $\begin{array}{c}\text { Onutai, S., Jiemsirilers, S., } \\
\text { Thavorniti, P., \& Kobayashi, T. } \\
\text { (2016) }\end{array}$ & - & - & - & - & - & - & 2.5 & $2-15$ & $\begin{array}{l}\text { Microwave } 200-850 \mathrm{~W} \\
\text { Heat Curing } 8024 \mathrm{~h}\end{array}$ & - & \\
\hline $\begin{array}{l}\text { Atiş, C. D., Görür, E. B., } \\
\text { Karahan, O., Bilim, C., } \\
\text { İlkentapar, S., \& Luga, E. (2015) }\end{array}$ & 450 & - & 0 & 150 & 0 & 1350 & - & - & HC $45-11524-72 \mathrm{~h}$ & 1-day: 120 & $\mathrm{Na}$ is $14 \%$ of mix weight \\
\hline
\end{tabular}

* SP: superplasticizer; CA: coarse aggregate; FA: fine aggregate; n/s sodium silicate to sodium hydroxide ratio; $\mathrm{M}_{\mathrm{NaOH}}$ : molar concentration of NaOH; $\mathrm{HC}$ : heat curing; AC: ambient curing; GLSS: granulated lead smelter slag; WRS: washed river sand; UFFA: ultra-fine fly ash.

** Mix design adjusted based on the assumption that geopolymer mortars have a density of $1800 \mathrm{~kg} / \mathrm{m}^{3}$.

*** Mix design not disclosed. 
Table 2 Oxide composition of fly ash and GGBS

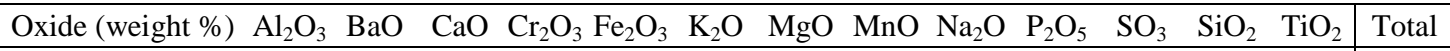
\begin{tabular}{llllllllllllll|l} 
Fly ash & 25.31 & 0.07 & 12.25 & 0.01 & 9.9 & 0.64 & 1.14 & 0.14 & 0.32 & 0.51 & 0.57 & 46.04 & 1.46 & 99.64
\end{tabular}

\begin{tabular}{llllllllllllllll} 
GGBS & 13.8 & 0.06 & 42.13 & 0 & 0.58 & 0.32 & 5.76 & 0.27 & 0.2 & 0.034 & 3.33 & 32.92 & 0.57 & 96.63 \\
\hline
\end{tabular}


Table 3 A summary of key experiment outcome including predicted Ec with Eq. 7, 8 and 9

\begin{tabular}{|c|c|c|c|c|c|c|c|c|c|c|}
\hline \multicolumn{2}{|c|}{ Specimen } & $\begin{array}{c}\text { Density } \\
\left(\mathrm{kg} / \mathrm{m}^{\wedge} 3\right)\end{array}$ & $\begin{array}{c}\text { Failure Stress } \\
(\mathrm{MPa})\end{array}$ & $\begin{array}{c}\mathrm{Ec} \\
(\mathrm{GPa})\end{array}$ & $\begin{array}{c}\text { Ec (Eq. 7, } \\
\text { GPa) }\end{array}$ & $\begin{array}{l}\text { Ec (Eq. } \\
8, \text { GPa) }\end{array}$ & $\begin{array}{c}\text { Ec (Eq. 9, } \\
\text { GPa) }\end{array}$ & $\mathrm{fcm}(\mathrm{MPa})$ & $\sigma(\mathrm{MPa})$ & $\mathrm{f}^{\prime} \mathrm{c}(\mathrm{MPa})$ \\
\hline \multirow{9}{*}{1 Day } & 1ATC1 & 2195.47 & 26.72 & - & - & - & - & \multirow{3}{*}{25.5} & \multirow{3}{*}{2.5} & \multirow{3}{*}{20.6} \\
\hline & 1ATC2 & 2174.30 & 22.70 & - & - & - & - & & & \\
\hline & 1ATC3 & 2197.56 & 27.14 & - & - & - & - & & & \\
\hline & 1SCB1 & 2178.03 & 51.19 & - & - & - & - & \multirow{3}{*}{49.3} & \multirow{3}{*}{2.7} & \multirow{3}{*}{43.9} \\
\hline & 1SCB2 & 2166.17 & 50.48 & - & - & - & - & & & \\
\hline & 1SCB3 & 2164.70 & 46.19 & - & - & - & - & & & \\
\hline & 1SCG1 & 2196.09 & 43.73 & - & - & - & - & \multirow{3}{*}{43.4} & \multirow{3}{*}{2.6} & \multirow{3}{*}{38.2} \\
\hline & 1SCG2 & 2200.07 & 45.91 & - & - & - & - & & & \\
\hline & 1SCG3 & 2185.40 & 40.70 & - & - & - & - & & & \\
\hline \multirow{9}{*}{3 Day } & 3ATC1 & 2213.00 & 44.29 & 22.696 & 29.793 & 33.610 & 28.996 & \multirow{3}{*}{43.7} & \multirow{3}{*}{0.6} & \multirow{3}{*}{42.5} \\
\hline & $3 \mathrm{ATC} 2$ & 2188.00 & 43.11 & 18.541 & 28.895 & 33.157 & 28.698 & & & \\
\hline & 3ATC3 & 2186.00 & 43.78 & - & - & - & - & & & \\
\hline & 3SCB1 & 2161.00 & 70.36 & 24.253 & 36.234 & 42.360 & 34.748 & \multirow{3}{*}{68.6} & \multirow{3}{*}{2.0} & \multirow{3}{*}{64.7} \\
\hline & 3SCB2 & 2168.00 & 68.86 & 25.944 & 36.020 & 41.906 & 34.450 & & & \\
\hline & 3SCB3 & 2167.00 & 66.49 & 26.797 & 35.369 & 41.178 & 33.971 & & & \\
\hline & 3SCG1 & 2189.00 & 58.30 & 24.566 & 33.625 & 38.558 & 32.249 & \multirow{3}{*}{59.1} & \multirow{3}{*}{3.0} & \multirow{3}{*}{53.2} \\
\hline & 3SCG2 & 2181.00 & 62.44 & 25.082 & 34.607 & 39.903 & 33.133 & & & \\
\hline & 3SCG3 & 2210.00 & 56.64 & - & - & - & - & & & \\
\hline & 7ATC1 & 2191.53 & 54.43 & 28.583 & 32.548 & 37.259 & 31.395 & & & \\
\hline & 7ATC2 & 2201.71 & 56.17 & 29.149 & 33.295 & 37.849 & 31.783 & 53.5 & 3.2 & 47.2 \\
\hline & 7ATC3 & 2184.41 & 50.03 & - & - & - & - & & & \\
\hline & 7SCB1 & 2176.97 & 85.53 & - & - & - & - & & & \\
\hline 7 Day & 7SCB2 & 2195.53 & 86.36 & - & - & - & - & 85.5 & 0.9 & 83.7 \\
\hline & 7SCB3 & 2184.78 & 84.58 & - & - & - & - & & & \\
\hline & 7SCG1 & 2162.57 & 61.66 & 31.935 & 33.957 & 39.655 & 32.970 & & & \\
\hline & 7SCG2 & 2162.53 & 69.58 & - & - & - & - & 66.9 & 4.6 & 57.8 \\
\hline & 7SCG3 & 2163.89 & 69.59 & - & - & - & - & & & \\
\hline & 14ATC1 & 2220.08 & 71.46 & - & - & - & - & & & \\
\hline & 14ATC2 & 2170.93 & 65.10 & - & - & - & - & 69.4 & 3.8 & 61.9 \\
\hline & 14ATC3 & 2201.27 & 71.76 & - & - & - & - & & & \\
\hline & 14SCB1 & 2186.26 & 88.57 & - & - & - & - & & & \\
\hline 14 Day & $14 \mathrm{SCB} 2$ & 2195.00 & 86.77 & 32.293 & 41.190 & 47.040 & 37.825 & 87.0 & 1.5 & 84.1 \\
\hline & 14SCB3 & 2194.57 & 85.67 & - & - & - & - & & & \\
\hline & 14SCG1 & 2169.51 & 73.63 & - & - & - & - & & & \\
\hline & 14SCG2 & 2175.18 & 70.33 & - & - & - & - & 72.6 & 2.0 & 68.6 \\
\hline & 14SCG3 & 2202.35 & 73.96 & 31.092 & 38.219 & 43.429 & 35.451 & & & \\
\hline & 28ATC1 & 2221.44 & 80.04 & 31.950 & 40.279 & 45.180 & 36.603 & & & \\
\hline & 28ATC2 & 2185.52 & 80.17 & 36.396 & 39.339 & 45.218 & 36.627 & 78.1 & 3.5 & 71.0 \\
\hline & 28ATC3 & 2175.08 & 73.98 & 31.135 & 37.518 & 43.436 & 35.456 & & & \\
\hline & 28SCB1 & 2203.63 & 95.16 & 39.703 & 43.391 & 49.262 & 39.286 & & & \\
\hline 28 Day & 28SCB2 & 2214.92 & 90.57 & 34.466 & 42.658 & 48.061 & 38.496 & 92.0 & 2.7 & 86.5 \\
\hline & 28SCB3 & 2208.96 & 90.26 & 26.793 & 42.414 & 47.979 & 38.442 & & & \\
\hline & 28SCG1 & 2218.14 & 85.96 & - & - & - & - & & & \\
\hline & 28SCG2 & 2180.32 & 77.66 & 31.047 & 38.579 & 44.504 & 36.158 & 80.4 & 4.8 & 70.8 \\
\hline & 28SCG3 & 2196.21 & 77.61 & 30.637 & 38.990 & 44.490 & 36.149 & & & \\
\hline
\end{tabular}

Table 4 Proposed coefficient a and $\mathrm{b}$ of Eq. 1 for ATC, SCG and SCB geopolymers

\begin{tabular}{ll}
\hline \multicolumn{2}{c}{ Coefficient $a$ Coefficient $b$} \\
\hline OPC 4 & 0.85 \\
ATC 2.5 & 0.95 \\
SCB 1 & 0.95 \\
SCG 1 & 1 \\
\hline
\end{tabular}


Table 5 EDS element analysis of 28-day geopolymer specimens

\begin{tabular}{ccccccccc}
\hline & $\mathrm{Si}($ atomic\%) & $\mathrm{Al}($ atomic\%) & $\mathrm{Na}($ atomic\%) & $\mathrm{Ca}($ atomic\%) & $\mathrm{Si} / \mathrm{Al}$ & $\mathrm{Ca} / \mathrm{Si}$ & $\mathrm{Ca} / \mathrm{Na}$ & $\mathrm{Al} / \mathrm{Ca}$ \\
\hline 28ATC & 9.07 & 2.97 & 7.39 & 6.00 & 3.05 & 0.66 & 0.81 & 0.50 \\
28SCG & 11.33 & 4.23 & 5.58 & 7.72 & 2.68 & 0.68 & 1.38 & 0.55 \\
28SCB & 10.95 & 4.62 & 4.56 & 8.60 & 2.37 & 0.79 & 1.89 & 0.54 \\
\hline
\end{tabular}

Table 6 Residual total alkalinity of 1, 3, 7 and 14-day specimens

\begin{tabular}{|c|c|c|c|c|c|c|c|c|c|c|c|c|}
\hline Spe & 1ATC & $1 \mathrm{SCG}$ & $1 \mathrm{SCB}$ & 3ATC & $3 \mathrm{SCG}$ & $3 \mathrm{SCB}$ & 7ATC & $7 \mathrm{SCG}$ & $7 \mathrm{SCB}$ & 14ATC & $14 \mathrm{SCG}$ & $14 \mathrm{SCB}$ \\
\hline $\begin{array}{c}\text { Residual total } \\
\text { alkalinity (mol) }\end{array}$ & 0.38 & 0.36 & 0.3 & 0 & 0. & 0 & 0 & 0.2 & 0. & 0 & 0. & \\
\hline
\end{tabular}

